\title{
The Virtual Child: Evaluation of an Internet- Based Pediatric Behavior Management Simulation
}

\author{
James R. Boynton, D.D.S., M.S.; Thomas G. Green, Ph.D.; Lynn A. Johnson, Ph.D.; \\ S.M. Hashim Nainar, B.D.S., M.D.Sc.; Lloyd H. Straffon, D.D.S., M.S.
}

Abstract: This article describes an Internet-based instructional tool designed to give predoctoral dental students a virtual simulation of clinical pediatric dentistry to develop their pediatric behavior management knowledge. Effectiveness of this tool was evaluated using two consecutive classes of junior dental students. The control group was exposed to the traditional behavior management curriculum (two lectures) in a spring term course. The next class of dental students was exposed to the two lectures and, in addition, completed the behavior management simulation during the following spring term. Both groups completed a two-part examination (objective section=18 questions; open-ended section=responses to a clinical situation) designed to test their behavior management knowledge. The simulation group performed significantly better in both parts of the examination (objective section: $\mathrm{p}=.028$; open-ended section: $\mathrm{p}=.012$ ). The simulation was evaluated by students and perceived by most to be an effective addition to the curriculum. It was concluded that the experimental behavior management simulation, when added to the traditional lecture curriculum, improved pediatric behavior management knowledge in predoctoral dental students.

Dr. Boynton is Clinical Assistant Professor, Department of Orthodontics and Pediatric Dentistry, University of Michigan School of Dentistry; Dr. Green is Lecturer, Department of Periodontics and Oral Medicine, and Director, Predoctoral Studies, University of Michigan School of Dentistry; Dr. Johnson is Associate Professor, Department of Periodontics and Oral Medicine, and Director of Dental Informatics, University of Michigan School of Dentistry; Dr. Nainar is Associate Professor, Division of Pediatric Dentistry, Department of Dentistry, Faculty of Medicine and Dentistry, University of Alberta, Edmonton, Alberta, Canada; and Dr. Straffon is Professor Emeritus, Department of Orthodontics and Pediatric Dentistry, University of Michigan School of Dentistry. Direct correspondence and requests for reprints to Dr. James R. Boynton, Department of Orthodontics and Pediatric Dentistry, School of Dentistry, University of Michigan, 1011 North University Avenue, Ann Arbor, MI 48109-1078; 734-763-2331 phone; 734-615-7294 fax; jboynton@umich.edu.

This article is based upon a thesis submitted by Dr. Boynton in partial fulfillment of the requirements for the degree of Master of Science in Pediatric Dentistry at the University of Michigan.

Key words: dental education, Internet, computer simulation, patient simulation, computer-assisted instruction, pediatric dentistry

Submitted for publication 1/22/07; accepted 5/22/07

$\mathrm{T}$ The predoctoral pediatric dentistry curriculum is typically taught in three main formats: didactic instruction, traditionally imparted via lectures and textbooks; hands-on simulation in a preclinical setting; and finally, when competence has been shown in the previous two formats, patient contact in a clinical setting. Students routinely simulate procedures and practice skills before actually performing them on patients. One essential pediatricbased skill set that is not routinely simulated is child behavior management. Students hear about child behavior management techniques in lectures, read about them in textbooks, and perhaps see examples in videos - and are then expected to achieve competence in the use of these skills in a clinical setting without prior "practice" via simulation.

There are a number of ways to simulate clinical experiences in medicine and dentistry, including physical simulators (such as manikin-based training), simulated patients (standardized patient interactions), interactive computer simulations, or any combination of these three. The goal of simulations remains the same: to practice in a simulated setting before practicing on persons in an actual clinical setting. ${ }^{1}$ Physical simulations cannot easily simulate a child's behavior. Children as young as age seven have acted as simulated patients, ${ }^{2}$ though teaching a child to "react" to a physician's history and physical examination is quite different from teaching a child to both misbehave during operative/surgical dentistry and appropriately react to the dental student's behavior management techniques. Other complicating issues with standardized child patients include the "substantially greater cost than traditional teaching" 3 associated with this technique as well as the fact that most behavior management skills are primarily necessary for pre-school-aged patients, an age group that has not yet been utilized as standardized patients 
primarily because they would obviously be difficult to train. For these reasons, it may not be feasible to use simulated patients to provide educational opportunities for dental students to practice pediatric behavior management.

An alternative is to simulate a child patient utilizing computer technology. Computer-based instruction (CBI) has been used in health education since the 1960s and has grown considerably in recent years as information technology has become more sophisticated. ${ }^{4}$ Interactive patient simulations in the field of dentistry can act as a bridge between the preclinic and clinic, from basic science to applied science, and from theoretical to real patients. Students can practice their hands-on skills using simulationbased training before their actual first encounter with live patients in a clinical setting. ${ }^{5}$ Other advantages include improvements in the quality and efficiency of dental education by making instruction more direct, better visualized, and more comprehensible, ${ }^{6}$ enabling opportunities to develop and practice critical thinking skills, ${ }^{7}$ and helping students in the transition from acquiring concepts to complex "doctor thinking." have recently been created to help academic dentists create computer-based patient simulations. ${ }^{9}$

For our study, a CBI tool was developed to simulate clinical experience in the dental treatment of a child. The goal of this tool, called "The Virtual Child," was to increase students' didactic knowledge of key concepts in pediatric behavior management through simulation. The purpose of this study was to examine the effectiveness of the addition of this webbased CBI tool to a traditional lecture experience as compared to the traditional lecture experience alone and to evaluate student perceptions of this tool.

\section{Methods and Materials}

After being granted an exemption from the Institutional Review Board, two consecutive classes of predoctoral dental students at the University of Michigan were included in this study. The classes were separately enrolled in two consecutive years in a didactic pediatric dentistry course delivered to dental students at the commencement of their junior year. This advanced, lecture-based course is taken as students begin their pediatric dental clinical rotations. This course included two fifty-minute lectures on the concepts and techniques of child behavior management. Both lectures were delivered in each of the two years of the study by the same faculty member using the same lecture notes. This pediatric dentistry faculty member had given these lectures for more than twenty years.

The first class of junior dental students served as the control group for this study. A total of 109 students were enrolled in this course during the 2003 iteration. They received the two fifty-minute lectures on behavior management and completed a two-part examination six weeks after the initial lecture.

The junior dental class taking the course the following year served as the experimental (simulation) group. A total of ninety-eight students were enrolled in this course during the 2004 iteration. This class received the two fifty-minute lectures on child behavior management. In addition, each student was required to visit the web-based instructional tool "The Virtual Child." Visiting the website was listed as a course requirement, though no attempts were made to verify student compliance. Six weeks following the initial lecture, each student completed the same two-part examination that was used the previous year.

Since the timing of the examination in the curriculum was similar in the two groups, each group was expected to have had equivalent amounts of clinical pediatric dentistry experience. As sophomore predoctoral students, each student would have had, in groups of two or three students, limited clinical encounters with well-behaved children for new patient or recall examinations. At the time of the examination used in this study, approximately 60 percent of each class of junior students had already completed their first junior pediatric clinical rotation, an eight half-day experience involving two half-days of physical simulations and small group seminars, and six half-days of patient care including more complex pediatric treatment such as restorations and extractions. The remaining 40 percent of each group at the time of the examination had not yet completed this clinical rotation.

The two-part examination developed for this study was designed to test knowledge regarding behavior management in pediatric dentistry and consisted of eighteen objective questions and one short answer essay question. The examination was reviewed by four pediatric dentists on faculty at the University of Michigan for appropriateness of content. The objective section of the examination included fourteen true-false questions, three fill-in-the-blank questions, and one multiple-choice question. The short answer essay portion of the examination was based on a clinical situation. It asked: "A four-year-old child refuses 
to open his mouth for an examination and prophylaxis. List as many options as you can think of to gain the child's cooperation." A list of thirteen possible acceptable responses was developed and used to score the students' responses to the open-ended question. Each class was allowed fifteen minutes to complete the anonymous examination.

The eighteen items of the objective section were scored individually and totaled. The open-ended question was scored individually based on the number of appropriate responses listed by the student. All results were entered into Microsoft Excel ${ }^{\circledR}$, exported to and analyzed with $\operatorname{SPSS} \AA$ version 11.5 .2 .1 . Statistical significance was set at $\mathrm{p}=0.05$.

The CBI tool designed for this study, called "The Virtual Child," was developed by the principal investigator (JRB) using Sitemaker ${ }^{\circledR}$, a proprietary website creation program. Students used their valid university login and password to access the website. Students could access the site as many times as they saw fit from any Internet-accessible computer.

The content of the website was based upon a fictitious seven-year-old child who was coming to the children's dentistry clinic for operative dental needs. The dental students interacted with this virtual child patient in the following manner: a text-based description of a situation prompted the student to select an action from a list of options. Based on the option selected, the virtual child patient "reacted," and the student was forwarded to a new webpage with a textbased description of the consequence of the student's choice. Pertinent pediatric dentistry information was brought to the students' attention as appropriate during this virtual appointment. Though consequences of poor choices were shown, the simulation was designed to not allow the student to proceed to the next step in the virtual appointment until the correct option was chosen. Two hundred individual webpages constituted the website. It included the following thirteen chapters: patient introduction; sitting in the chair; setting of rules; "are you going to pull a tooth?"; topical anesthetic; local anesthesia introduction; "will it hurt?"; the local anesthesia process; rubber dam isolation; tooth preparation; Jimmy's hands move up; extraction; and post-operative discussion. Four of the 200 individual pages that made up the simulation tool are shown in Figure 1.

For evaluation of "The Virtual Child" CBI tool, a fourteen-item Likert scale questionnaire was included with the test packet given to the experimental group of students in year two of the study. Students responded to each of the statements using the following scale: $1=$ strongly disagree, $2=$ disagree, $3=$ neutral, $4=$ agree, $5=$ strongly agree.

\section{Results}

One hundred and seven students in the control group completed the examination. Two students did not complete the examination due to their absence from the class on the date of the examination. All ninety-eight students in the simulation (experimental) group completed the examination. Each student in both the groups was also asked if the student had begun or completed his or her first junior pediatric dentistry clinical rotation. Of the 107 students in the control group, sixty-four (59.8 percent) had already completed their first pediatric clinical rotation. The remaining forty-three students (40.1 percent) had not. Of the ninety-eight students in the simulation group, sixty (61.2 percent) had already completed their first pediatric clinical rotation, while the remaining thirtyeight (38.8 percent) had not.

The mean total score for the control group on the objective section of the exam was 13.45 $(\mathrm{SD}=2.26)$. The mean objective section total score for the simulation group was $14.08(\mathrm{SD}=1.83)$. A $t$-test for equality of means showed a statistically significant difference between the groups ( $p=.028)$. The number of correct responses to the open-ended question asked on the examination was analyzed. The mean number of correct responses for the control group was $3.02(\mathrm{SD}=1.01)$. The mean number of correct responses to the open-ended question for the simulation group was $3.39(\mathrm{SD}=1.07)$. A $t$-test for equality of means showed a statistically significant difference between the two groups $(\mathrm{p}=.012)$. The information is summarized in Table 1.

To assess the potential effect of junior pediatric dental clinic rotation experience on examination results, data were analyzed to determine differences between the control group with clinic experience and the simulation group without clinic experience. Sixty-four of 107 students in the control group had completed their first clinical rotation in the pediatric dentistry clinic at the time the examination was administered. The mean total score of this subgroup within the control group on the objective section of the examination was $14.00(\mathrm{SD}=1.95)$, and these students had a mean of $3.09(\mathrm{SD}=.94)$ on the openended section. Among the simulation group, thirtyeight of ninety-eight students had not yet had their junior clinical rotation in the pediatric dentistry 
BEGIN HERE:

You are now ready to escort Jimmy back to the operatory and begin. What do you say?

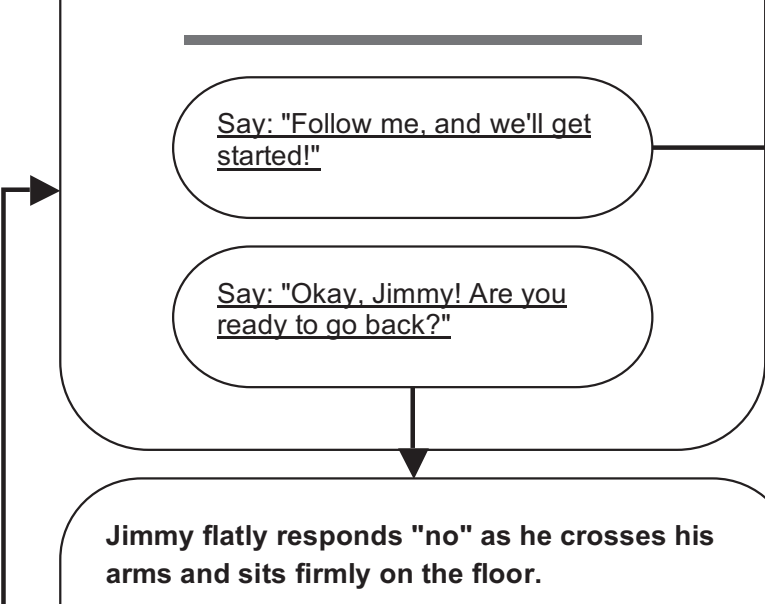

You try and coax him to get up, but he keeps repeating, "I'M NOT READY YET!"

You try for 15 minutes to get Jimmy to stand up, but he will not, saying, "I'm still not ready!" The appointment must be rescheduled.

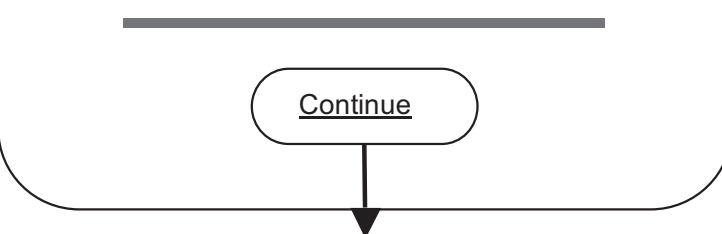

\section{IMPORTANT PEDIATRIC DENTISTRY INFORMATION:}

Though most children will gladly say "yes!" to this type of question, the dentist should not make obligatory actions (such as going back to the chair) optional. Asking a question such as "are you ready?" gives a child an opportunity to say "NO." Put yourself in the shoes of a child: would you ever be ready to go back and lie down in a stranger's chair for an hour while she does all this strange stuff in your mouth? Instead, give simple, firm, polite commands to children.

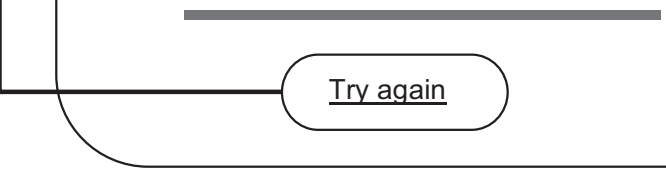

Note: Each box in the figure represents a separate webpage. Underlined portions represent hyperlinks with arrows indicating which page is linked.

Figure 1. Schematic representation of "The Virtual Child" website with snapshot of four webpages 
clinic. The students in the simulation group without clinical experience had a total mean score of 13.71 $(\mathrm{SD}=1.92)$ on the objective section and a mean score of $3.13(\mathrm{SD}=.99)$ on the open-ended section. A $t$-test for independent means was completed, and p-values for both total score and number of correct responses to the open-ended question indicated that differences were not statistically significant. A summary of this information is found in Table 2.

Ninety-seven students completed the subjective evaluation of "The Virtual Child" CBI tool (one evaluation was blank and was not included in the analysis). A summary of the means and standard deviations is found in Table 3.

\section{Discussion}

The objective of this study was to examine the effectiveness of an Internet-based pediatric behavior management tool in enhancing predoctoral dental students' didactic knowledge of key concepts in behavior management of children. This study found that dental students who had been exposed to the simulation performed significantly better on an examination regarding knowledge of pediatric behavior management than did the control group (Table 1). Whether simply due to the additional exposure of course material via the simulation or due to the interactive nature of the material presented, addition of this CBI

Table 1. Examination scores: control group vs. simulation group

\begin{tabular}{|c|c|c|c|c|c|c|c|}
\hline \multirow[t]{2}{*}{ Examination } & \multicolumn{2}{|c|}{ Control $(n=107)$} & \multicolumn{2}{|c|}{ Simulation $(n=98)$} & \multirow[b]{2}{*}{$\mathrm{T}$} & \multirow[b]{2}{*}{ df } & \multirow[b]{2}{*}{ p-value } \\
\hline & Mean & $\mathrm{SD}$ & Mean & SD & & & \\
\hline Objective section score & 13.45 & 2.26 & 14.08 & 1.83 & 2.22 & 200.01 & .028 \\
\hline Open-ended section score & 3.02 & 1.01 & 3.39 & 1.07 & 2.53 & 198.68 & .012 \\
\hline
\end{tabular}

Table 2. Examination scores: control group with clinic experience vs. simulation group without clinic experience

\begin{tabular}{|c|c|c|c|c|c|c|c|}
\hline \multirow[t]{2}{*}{ Examination } & \multicolumn{2}{|c|}{ Control $(n=64)$} & \multicolumn{2}{|c|}{ Simulation $(\mathrm{n}=38)$} & \multirow[b]{2}{*}{$\mathrm{T}$} & \multirow[b]{2}{*}{ df } & \multirow[b]{2}{*}{ p-value } \\
\hline & Mean & $\mathrm{SD}$ & Mean & $\mathrm{SD}$ & & & \\
\hline Objective section score & 14.00 & 1.95 & 13.71 & 1.92 & .73 & 100 & .468 \\
\hline Open-ended section score & 3.09 & .94 & 3.13 & .99 & -.19 & 74.46 & .850 \\
\hline
\end{tabular}

Table 3. Dental students' $(n=97)$ evaluation of "The Virtual Child" computer-based instruction tool on a scale of 1 (strongly disagree) to 5 (strongly agree)

\begin{tabular}{lcc} 
& Mean & Std. Dev. \\
\hline The Virtual Child website (TVC) improved my knowledge of behavior management. & 3.90 & .420 \\
TVC improved my confidence in treating children. & 3.47 & .663 \\
TVC was a more effective way of learning than lectures on behavior management. & 3.69 & .727 \\
I would prefer to learn behavior management only from TVC. & 2.70 & .915 \\
I would prefer to learn behavior management from TVC and lecture together. & 3.96 & .720 \\
I would prefer to learn behavior management from lecture alone. & 2.57 & .776 \\
I would like to experience more computer-based simulations in future courses. & 3.67 & .625 \\
I feel more confident giving local anesthesia to a child after completing TVC. & 3.04 & .923 \\
TVC was redundant, mindless busywork. & 2.54 & .817 \\
I will visit TVC before my next pediatric dentistry rotation. & 3.20 & .943 \\
I would rather visit TVC than lecture notes to review this topic. & 3.38 & .871 \\
I am comfortable using computers in my dental education. & 4.23 & .604 \\
I am better prepared to treat children after having visited TVC. & 3.61 & .622 \\
I made mistakes on TVC that I now know to avoid when treating a real child. & 3.75 & .646
\end{tabular}


tool to a traditional lecture curriculum increased examination scores when compared to a control group that had only received lectures. The supplementation of lecture (as opposed to its replacement) with computer-based simulations has been shown in other studies to increase examination scores. ${ }^{10,11}$

It was interesting to note the response of the control and simulation groups to an open-ended question regarding behavior management for an uncooperative four-year-old child who presents for an examination and prophylaxis. This section was graded based on the number of valid management options provided by the students in response to the clinical situation. The ability of the simulation group to provide significantly more correct responses (3.39 vs. 3.02) is a promising finding. The simulation group may have had better retention of the behavior management techniques based on their additional exposure, or perhaps the simulation of these techniques with "The Virtual Child" gave these students a type of experience that promoted retention in memory.

There were no significant differences in performance on the objective examination and the openended question in the simulation group without pediatric clinical experience and the control group with pediatric clinical experience (Table 2). Our review of the literature was not able to identify any previous studies that compared students' examination performance based on whether they had received clinical training versus completion of web-based modules without clinic experience. This is noteworthy: the data demonstrate no significant differences in examination scores between those using a CBI tool and those completing an advanced six half-day clinical rotation. A possible explanation for this finding may be that students in both groups have had some type of pediatric experience - the control group had reallife experience whereas the CBI group had virtual experience. Students who complete simulations have been shown to improve their clinical decision-making skills. ${ }^{12}$ It is plausible that students who complete this $\mathrm{CBI}$ tool prior to their clinical experience in pediatric dentistry may demonstrate better clinical judgment in the arena of child behavior management. This in turn may lead to better clinical experiences for the dental student, as well as the child patient the student is treating. Potential validity of this finding is, however, limited due to the fact all students had had some pediatric clinical experience as sophomores (albeit in groups) and the questionable clinical significance of a short pediatric dental clinic rotation (six half-days of patient contact).
The results of the students' evaluation of "The Virtual Child" CBI tool revealed that computer simulation was perceived to be a generally positive learning activity. The simulation increased students' confidence in treating children, and students felt that it was an effective learning tool. The positive responses to the statement "I made mistakes on TVC that I now know to avoid when treating a real child" are of special importance (Table 3). Besides the educational value imparted to the dental student, an advantage may also be bestowed on the children who receive treatment from the dental student. CBI can create an environment of safe experimentation $^{13}$ - mistakes made on a computer program that are avoided with a real patient can lead to a better experience for the child patient.

A portion of the "The Virtual Child" evaluation dealt with students' preferred modality to learn behavior management:

- "I would prefer to learn behavior management only from TVC."

- "I would prefer to learn behavior management from TVC and lecture together."

- "I would prefer to learn behavior management from lecture alone."

Students overwhelmingly wanted to learn this information from both lecture and computer (Table 3 ). Others have found CBI to be a good additional class resource ${ }^{14}$ and even suggested CBI's most important purpose should be effective supplementation and reinforcement of material rather than its replacement. ${ }^{11}$ Some even hypothesize that students in the Internet age may resent being handed off to impersonal computer terminals. ${ }^{15}$

This study had several limitations. The examination itself was developed prior to the development of "The Virtual Child" website. Both the examination and the website were developed solely by the primary investigator (JRB). It is possible that the content of the examination was given more emphasis in the CBI tool in an unconscious effort to show examination improvement by the simulation group. Intact instructional groups were used; thus, the control and simulation groups were not randomized. The author was not blinded to the identity of each group during the grading of the examinations. No pre-test evaluations were done with either group to assess baseline knowledge. Examinations were completed anonymously by students, which may raise questions of their drive to do well on the examination. Due to the design of the study, the control group and the simulation group were not exposed to 
completely identical didactic lectures. Though both sets of lectures were undoubtedly similar, variations may have existed in their content and presentation. Additionally, the lecturer was aware that a research study was being conducted, which may have biased his presentation.

The examination content was verified by four pediatric dentists; however, it was not tested for reliability and validity. A recent review of the evaluation of educational software stated that, as a general rule for all demonstration studies (such as this study), reliability and validity of the measurement process should be reported. ${ }^{16}$

The clearest limitation is that results of the examination may not correlate with clinical competence. A statistically significant difference in examination scores between the two study groups may not be meaningfully significant, either clinically or otherwise. The experimental group's mean score of 14.08 was only 4.68 percent higher than the control group's mean score of 13.45 . Hence, the real significance of the experimental intervention remains unknown. Others have also questioned if increased test scores translate into clinical significance. ${ }^{15}$

Future studies may look to improve the design of the simulation with more media or export the template of the design to other clinical areas. Studies that attempt to compare real clinical performance with simulation experience and better quantify relationships between virtual and real experience are necessary as well.

\section{Conclusions}

The findings from this study suggest that an Internet-based pediatric behavior management simulation, when used as a supplement to a traditional lecture curriculum, may improve dental student knowledge when compared to lecture alone.

\section{REFERENCES}

1. Friedrich MJ. Practice makes perfect: risk-free medical training with patient simulators. JAMA 2002;288(22): 2808-12.

2. Lane JL, Ziv A, Boulet JR. A pediatric clinical skills assessment using children as standardized patients. Arch Pediatr Adolesc Med 1999;153(6):637-44.

3. Brown R, Doonan S, Shellenberger S. Using children as simulated patients in communication training for residents and medical students: a pilot program. Acad Med 2005;80(12):1114-20.

4. Tira DE, Tharp LB, Lipson LF. Computers in dental education: promise of the past versus reality of the present. Dent Clin North Am 1986;30(4):681-94.

5. Abbey LM. Interactive multimedia patient simulations in dental and continuing dental education. Dent Clin North Am 2002;46(3):575-87.

6. Wurdack CM. Multimedia-based education. Contact Point 1997;77(3):23-6.

7. Clancy JM, Johnson LA, Finkelstein MW, Lilly GE. Dental diagnosis and treatment (DDx \& Tx): interactive videodisc patient simulations for dental education. Comput Methods Programs Biomed 1990;33(1):21-6.

8. Hoban JD, Schlesinger JB, Fairman RP, Grimes MM. Electrifying a medical school course: a case study. Teach Learn Med 2003;15(2):140-6.

9. Abbey LM, Arnold P, Halunko L, Huneke MB, Lee S. Case studies for dentistry: development of a tool to author interactive, multimedia, computer-based patient simulations. J Dent Educ 2003;67(12):1345-54.

10. Gilbart MK, Hutchinson CR, Cusimano MD, Regehr G. A computer-based trauma simulator for teaching trauma management skills. Am J Surg 2000;179(3):223-8.

11. Fouad AF, Burleson JA. Effectiveness of an endodontic diagnosis computer simulation program. J Dent Educ 1997;61(3):289-95.

12. Johnson LA, Cunningham MA, Finklestein MW, Hand JS. Geriatric patient simulations for dental hygiene. J Dent Educ 1997;61(8):667-76.

13. Loke E, Lun KC. Virtual patients for a virtual hospital. Medinfo 1998;9(pt 2):1278-81.

14. Eynon R, Perryer G, Walmsley AD. Dental undergraduate expectations and opinions of web-based courseware to supplement traditional teaching methods. Eur J Dent Educ 2003;7(3):103-10.

15. Lieberman G, Abramson R, Volkan K, McArdle PJ. Tutor versus computer: a prospective comparison of interactive tutorial and computer-assisted instruction in radiology education. Acad Radiol 2002;9(1):40-9.

16. Schleyer TK, Johnson LA. Evaluation of educational software. J Dent Educ 2003;67(11):1221-8. 